\title{
A rare case of congenital absence of permanent canines associated with other dental anomalies
}

\author{
M GunaShekhar ${ }^{1}$, K. Srinivas Rao ${ }^{2}$, B. Dutta ${ }^{3}$ \\ ${ }^{1}$ Associate Professor, Faculty of Pediatric Dentistry, NTRUHS, AP, India. \\ ${ }^{2}$ Associate Professor, Faculty of Orthodontics, GDC, Vijayawada, AP, India. \\ ${ }^{3}$ Professor, Faculty of Pediatric Dentistry, NTRUHS, AP, India.
}

Correspondence:

\#160, $5^{\text {th }}$ Cross, $28^{\text {th }}$ Main, Sector-1, HSR Layout,

Bangalore -560102, INDIA.

E-mail:drguna1234@rediffmail.com

\begin{abstract}
Agenesis of permanent canines is a rare condition and that of both maxillary and mandibular permanent canines is extremely rare. Reports of such cases are very scarce in the literature. It may occur either isolated or in association with other dental anomalies. This paper reports an unusual case of agenesis of both the maxillary permanent canines and mandibular right permanent canine occurring in association with congenitally missing mandibular permanent central incisors and microdontic maxillary lateral incisors in a 10 year-old Indian male.
\end{abstract}

Key words: Agenesis, permanent canines, maxilla, mandible. 


\section{Introduction}

Congenital absence of one or more teeth from the dentition has been termed hypodontia. Prevalence of hypodontia in the permanent dentition (excluding 3rd molars) is about $4.5-7.4 \%$ in Caucasians (1) and the most frequently affected teeth are the mandibular second premolar $(3.4 \%)$ and the maxillary lateral incisor $(2.2 \%)$ (2). Congenital absence of the canines in the permanent dentition is very rare and the reported incidence varies from $0.18-0.45 \%(3,4,5)$. Studies have reported more predilections in females and in the maxilla $(3,4)$.

Dental anomalies associated with congenitally missing permanent canines include agenesis of other teeth, microdontia, malocclusion, and retained primary teeth (4). Congenital agenesis of permanent canines in both maxilla and mandible is extremely rare. This article describes a rare case of congenital absence of maxillary (bilateral) and mandibular (unilateral) canines associated with congenital agenesis of mandibular permanent central incisors and microdontic maxillary lateral incisors.

\section{Case Report}

A 10 year-old Indian male reported to the dental clinic with a complaint of slight pain in the mandibular left posterior region of 2-week duration. Past dental history revealed that his mandibular left primary second molar (75, FDI notation) was endodontically treated elsewhere 3 months back. His medical history was unremarkable. Intraoral examination showed that patient was in mixed dentition stage with deep carious lesions evident in $64,74,84,85$ and a provisional restoration in 75 . Maxillary left permanent central incisor was in crossbite relation. Further, both the mandibular deciduous central incisors were retained and the corresponding successors, permanent central incisors, were missing clinically. Family history revealed no such finding in any members of the family. A panoramic radiograph was taken to confirm hypodontia in permanent dentition, which revealed congenital agenesis of mandibular central incisors. Further, bilateral maxillary permanent canines and mandibular right permanent canine were seen congenitally missing. Both maxillary permanent lateral incisors appeared microdontic (peg-shaped) with incomplete root formation (Figure 1). Dental management included completion of endodontic treatment in 74 and 75 . Restoration of other carious teeth and orthodontic correction of crossbite was scheduled but unfortunately the patient was lost to further management and follow-up.

\section{Discussion}

The etiology of such an anomaly is obscure. Whilst racial difference in prevalence suggests that genetic factors may be a more probable reason to the congenital absence of teeth, variable etiology exists including hereditary, environmental or endocrine disturbances (6). Recent studies have reported that synergistic interaction of genes Pax9 and Msx1 may cause human tooth agenesis $(7,8)$.

Agenesis of permanent teeth has been strongly correlated to the absence of corresponding primary predecessors $(9,10)$. The present case showed agenesis of bilateral maxillary permanent canines, mandibular right permanent canine, and both the mandibular central incisors, while the corresponding predecessors were clinically present.

Fukuta (2004) had reported two cases, each of which

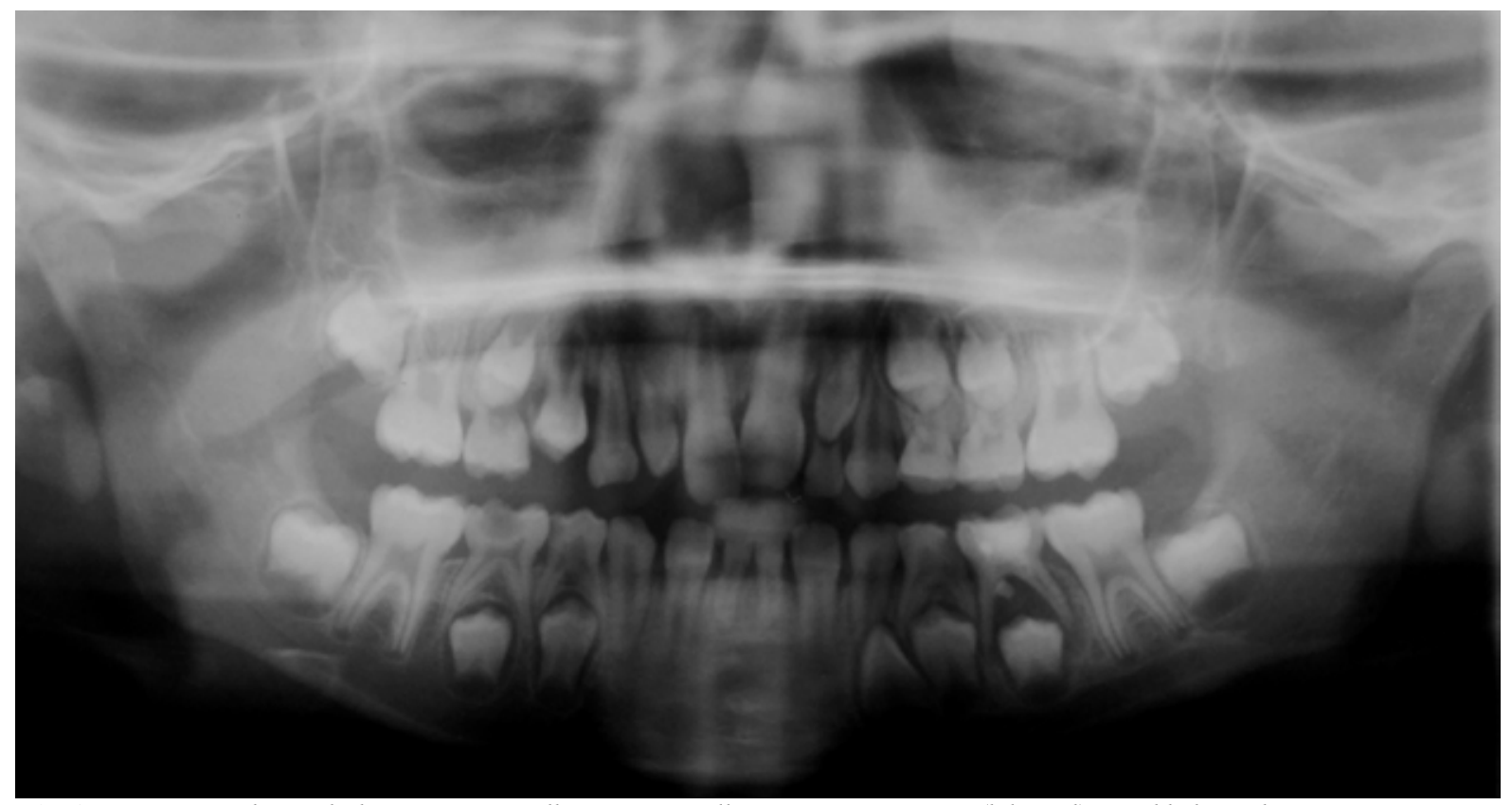

Fig. 1. Panoramic radiograph showing congenitally missing maxillary permanent canines (bilateral), mandibular right permanent canine, mandibular central incisors, and peg-shaped maxillary lateral incisors. 
showed absence of three permanent canines (3). The present case displayed agenesis of both the maxillary permanent canines and mandibular right permanent canine, and can be considered uncommon as maxillary and mandibular permanent canines were seldom found missing congenitally.

Strong association between hypodontia and microdontia has been suggested by Brook in his study. He further proposed a multifactorial model which related genetic and environmental influences to the anomalies of human tooth number and size $(11,12)$. Bazan had reported 2 cases of congenitally missing maxillary permanent canines associated with peg-shaped maxillary lateral incisors. According to her, absence of maxillary permanent canines, which develop before than lateral incisors, might result in the alteration of local environment at the time of development of adjacent unstable teeth thereby resulting in a reduction in size (13).

Cho et al. (2004) had reported three cases of congenitally missing maxillary permanent canines associated with microdontic bilateral maxillary permanent lateral incisors (peg shaped) (6). Similar association of peg-shaped maxillary lateral incisors with congenital absence of permanent canines was evident in our case.

Upper half of the mandibular symphysis exhibits significant/pronounced vertical and horizontal growth changes during childhood and puberty. Moreover, growth of alveolar bone, resulting in an increase in the height of the mandibular body, is associated with continuous eruption of teeth. Hence agenesis of mandibular incisors may impact the growth of alveolar bone in the mandibular symphyseal region (14).

Treatment approach has to be case specific and depends on condition of primary predecessor, number of missing teeth, status of occlusion/occlusal condition and patient/ parent's preferences. Timely extraction of primary predecessors can be considered to allow spontaneous space closure with or without further orthodontic alignment or the primary canines can be retained until replacement with a suitable restoration when they are lost (6). Our case displayed little or no resorption of retained primary canines at the time of diagnosis.

Primary canines without permanent successors might have reasonably longer survival rates and therefore would be functionally advantageous in subjects affected with severe hypodontia (15). Retaining the primary teeth in such cases may impede alveolar resorption until adolescent stage and help to preserve the volume of bone, for replacement with end-osseous implants in favorable locations, at a later time, without the need for bone grafting $(6,14)$.

\section{References}

1. Nordgarden H, Jensen JL, Storhaug K. Reported prevalence of congenitally missing teeth in two Norwegian counties. Community Dent Health. 2002;19:258-61.
2. Backman B, Wahlin YB. Variations in number and morphology of permanent teeth in 7-year-old Swedish children. Int J Paediatr Dent. 2001;11: 11-7.

3. Fukuta Y, Totsuka M, Takeda Y, Yamamoto H. Congenital absence of the permanent canines: a clinico- statistical study . J Oral Sci. 2004; 46: $247-52$.

4. Rozsa N, Nagy K, Vajo Z, Gabris K, Soos A, Alberth M et al. Prevalence and distribution of permanent canine agenesis in dental paediatric and orthodontic patients in Hungary. Eur J Orthod. 2009;31:374-9.

5. Davis PJ. Hypodontia and hyperdontia of permanent teeth in Hong Kong schoolchildren. Community Dent Oral Epidemiol. 1987; 15:21820.

6. Cho SY, Lee CK, Chan JC. Congenitally missing maxillary permanent canines: report of 32 cases from an ethnic Chinese population. Int J Paediatr Dent. 2004; 14:446-50.

7. Kapadia H, Mues G, D’Souza. Genes affecting tooth morphogenesis. Orthod Craniofac Res. 2007;10:105-13.

8. Nakatomi M, Wang XP, Key D, Lund JJ, Turbe-Doan A, Kist R et al. Genetic interaction between Pax9 and Msx1 regulate lip development and several stages of tooth morphogenesis. Dev Biol. 2010;340:43849.

9. Davis PJ, Darvell BW. Congenitally missing permanent mandibular incisors and their association with missing primary teeth in the southern Chinese (Hong kong). Community Dent Oral Epidemiol. 1993;21:162-4.

10. Whittington BR, Durward CS. Survey of anomalies in primary teeth and their correlation with the permanent dentition. N Z Dent J. 1996; 92: 4-8.

11. Brook AH. A unifying aetiological explanation for anomalies of human tooth number and size. Arch Oral Biol. 1984;29:373-8.

12. Brook AH, Elcock C, al-Sharood MH, McKeown HF, Khalaf K, Smith RN. Further studies of a model for the etiology of anomalies of tooth number and size in humans. Connect Tissue Res. 2002; 43:28995 .

13. Bazan MT. A congenitally missing canine in association with other dental disturbances: report of two cases. ASDC J Dent Child. 1983; 50:382-4.

14. Buschang PH, Julien K, Sachdeva R, Demirjian A. Childhood and pubertal growth changes of the human symphysis. Angle Orthod. 1992; 62:203-10.

15. Haselden K, Hobkirk JA, Goodman JR, Jones SP, Hemmings KW. Root resorption in retained deciduous canine and molar teeth without permanent successors in patients with severe hypodontia. Int J Paediatr Dent. 2001;11:171-8. 